\title{
Identificação, memória e figuras identitárias: a tensão entre a cristalização e o deslocamento de lugares sociais
}

Evandra Grigoletto (UFPE) Fabiele Stockmans De Nardi(IFPE)

\section{Resumo}

A proposta deste artigo é discutir a noção de figuras identitárias, observando como a memória intervém no processo de produção de sentidos, promovendo a cristalização e/ou o deslocamento de determinados lugares sociais. Essa noção se apoia no conceito de figura, que tomamos aqui enquanto cristalização, no tempo, de uma imagem que está colada à representação de um lugar social. A figura aparece como forma por meio da qual é possivel representar esse lugar, podendo sofrer deslocamentos ao ser discursivizada em diferentes épocas. Trata-se da forma material de um discurso fundador (ORLANDI, 2003) que marca o imaginário que se constrói sobre um grupo social. Ao ocuparmo-nos das figuras identitárias, traçamos como objetivos centrais deste artigo: 1) produzir uma teorização acerca dessa noção no campo da $A D$, a partir da relação entre os conceitos de figura, memória e identificação; 2) explorar a sua produtividade analítica, a partir das figuras do cangaceiro e do compadrito.

Palavras-chave: memória; figuras identitárias; identificação. 


\section{Palavras iniciais}

Este trabalho surge de uma inquietação acerca do funcionamento dos discursos que se produzem em torno de determinados lugares sociais, cuja presença-ausência continua ecoando ao longo do tempo - seja em narrativas histórias ou ficcionais, seja em discursos na internet -, ora como modo de designar a si mesmo, ora como forma de (des)identificar-se ao outro. Apesar de poderem apresentar funcionamentos diversos, esses lugares têm em comum o fato de participarem da construção identitária de grupos sociais. Observando, então, o funcionamento de alguns discursos acerca de personagens como o cangaceiro e o compadrito, chegamos à noção de figuras identitárias (DE NARDI; GRIGOLETTO, 2012). Entendemos que a figura representa a cristalização de elementos que caracterizam um lugar social, o qual passa a ser nuclear na construção identitária de um grupo, ainda que haja incessantes desdobramentos nos processos de (des)identificação dos sujeitos com esse lugar.

Partindo dessa reflexão, surgem alguns questionamentos que orientarão o percurso que realizaremos neste artigo. O que faz com que essas personagens se colem a diferentes épocas e discursos, fundando determinados lugares sociais? Qual o papel das figuras nas construções identitárias e qual o funcionamento da memória nesse processo? O que caracteriza o funcionamento de figuras como o cangaceiro e o compadrito nos discursos em análise?

Para refletir sobre essas questões, utilizaremos o referencial teórico da Análise do Discurso de linha pecheuxtiana, especialmente aqueles trabalhos que se dedicam a pensar as relações entre a memória e os processos de identificação. Inicialmente, vamos nos dedicar a discutir a noção de figuras identitárias para, em seguida, trabalharmos a sua relação com a noção de memória. Por fim, apresentaremos algumas análises de discursos produzidos em torno das figuras do cangaceiro e do compadrito.

\section{Figuras identitárias: especulações e desdobramentos}

O tratamento das figuras identitárias e de seu lugar nos processos identificatórios exige que pensemos, inicialmente, no que vamos entender, neste trabalho, como lugar social. Ao situarmo-nos no campo da Análise do Discurso, somos levados a observar as relações entre os diferentes espaços que são colocados em jogo nos processos discursivos. Embora não se trabalhe na $\mathrm{AD}$ com o sujeito empírico, tampouco com uma cisão entre os espaços empírico e discursivo, é preciso levar em consideração as determinações sócio-histórico-ideológicas às quais o sujeito está exposto ao inscrever-se no discurso. Conforme reflexão feita por Grigoletto (2008, p. 53), entendemos o lugar social "como ponto de ancoragem para a constituição da prática discursiva". Assim, os diferentes lugares sociais que todos nós podemos ocupar, en- 
quanto sujeitos empíricos, ao mesmo tempo determinam e são determinados pelas práticas discursivas. "O sujeito sempre fala de um determinado lugar social, o qual é afetado por diferentes relações de poder, e isso é constitutivo do seu discurso. Então, é pela prática discursiva que se estabiliza um determinado lugar social/empírico." (GRIGOLETTO, 2008, p. 54). A noção de figura, tal como estamos entendendo aqui, funciona, no interior dessas práticas, contribuindo para a cristalização e/ou deslocamento de determinados lugares sociais, representativos de grupos específicos que fazem parte da história de um povo: o cangaceiro e o compadrito. Embora funcionem de forma diversa, essas são figuras emblemáticas nos discursos sobre a constituição identitária do nordestino e do porteño. Pêcheux (1975) traz o exemplo do soldado francês ${ }^{1}$, mostrando como a norma identificadora determina os lugares sociais de cada sujeito, sob o efeito do ideológico. Portanto, os lugares sociais ocupados pelos sujeitos em uma formação social já são moldados em função de condições histórico-ideológicas específicas. Assim, ao dizer, inscrever-se num determinado discurso, o sujeito carrega traços desse lugar que ocupa socialmente. No entanto, esses lugares, embora mais estáveis quando se situam no espaço empírico, podem sofrer deslocamentos/atualizações ao serem discursivizados. O que nos interessa aqui é justamente observar como esses deslocamentos são operados em discursos atuais que tematizam as figuras do cangaceiro e do compadrito.

Ao propormos a noção de figuras identitárias, pensamos (DE NARDI; GRIGOLETTO, 2012) em um conceito que nos permitisse analisar os processos discursivos mediante os quais se produzem, em determinados grupos sociais, identidades locais que se personificam, funcionando como lugares historicamente constituídos cujos traços vão deixando marcas na constituição identitária do sujeito. Portanto, tratar do funcionamento dessas figuras exige que pensemos na própria noção de identidade e sua compreensão dentro do quadro teórico do AD.

Compreender a identidade como uma construção marcada pela historicidade é o que buscamos neste trabalho, por isso, ao pensar as identidades nacionais, voltamo-nos para Hall (2006), que nos mostra ser a sua produção o resultado de um processo de enfrentamento com o outro, seja para negá-lo, seja para aceitar a heterogeneidade e o hibridismo como elementos dessa identidade que se institui. Para o autor, importa lembrar, no entanto, que por trás de todo o desejo de unidade há sempre o risco de se suprimir tanto as diferenças culturais, quanto a historicidade inscrita em todo processo de construção de identidades. Assim, ainda que não vivamos mais o tempo das identidades nacionais, tais reflexões nos interessam porque todos os processos de globalização podem levar a um apagamento do local em nome da criação de uma universalidade. A reação a esse apagamento pode ser, contraditoriamente, o retorno ao local, o que instaura a

"Um soldado francês não recua", significa, portanto, "se você é um verdadeiro soldado francês, o que, de fato, você é, então você não pode/deve recuar". (PÊCHEUX, 1997, p. 159) 
necessidade, segundo o autor, de considerarmos a tensão entre o global e o local, observando como ela está se articulando.

A atualização do que temos chamado de figuras identitárias faz com que nos inscrevamos justamente nesse espaço de tensão para observar se, em alguma medida, essas figuras ainda podem ser consideradas espaços de identificação dos/para os sujeitos que fazem parte dos grupos sociais de que elas são representativas. Isso, no entanto, não pode ser feito antes de observarmos que a noção de identidade, quando deslocada para o campo da AD, leva-nos a Pêcheux (1997, p. 155) e sua consideração de que a "evidência" da identidade oculta que esta resulta de uma identificação-interpelação do sujeito, cuja origem estranha é, contudo, "estranhamente familiar". Tal evidência produz o ocultamento da cisão, da movência inerente aos processos discursivos por meio dos quais a identidade aparece como se fosse UNA. O sujeito, ao ignorar a sua condição de assujeitado, constitui-se enquanto fonte e origem do seu dizer e, no repetir incessante dessa suposta unidade, fabrica-se a cristalização de UM sentido, de UMA identidade, de UM lugar social.

Capturar A identidade está, para a AD, na ordem do impossível, e é por isso que, ao questionar essa evidência, passa-se a trabalhar com os processos de identificação, procurando compreender momentos de identificação ${ }^{2}$ por que passa o sujeito, imerso na dispersão. Para o sujeito da AD, queé "fruto de múltiplas identificações - imaginárias e/ou simbólicas - com traços do outro que, como fios que se tecem e se entrecruzam para formar outros fios, vão se entrelaçando e construindo a rede complexa e híbrida do inconsciente e, portanto, da subjetividade." (CORACINI, 2003, p. 203), não há nunca uma identidade que esteja pronta e a qual ele possa se acomodar definitivamente: falamos de um sujeito do/no discurso, atravessado pela ideologia e pelo inconsciente, rodeado por espaços de identificação com que se filia (ou não) e a partir dos quais constrói um lugar de dizer. Trata-se de um sujeito imerso em um processo constante de movimentos de (des)identificação em sua relação com o simbólico, movimentos ancorados no imaginário que se constrói sobre determinados lugares sociais, os quais abrigam, em sua discursividade, dizeres e sentidos que ecoam/ressoam em diferentes momentos sócio-históricos.

Entendemos que é justamente a análise dessas discursividades que nos levará aos indícios de como se constituem e trabalham as figuras identitárias no processo de (re)construção de identidades locais e/ou regionais. Ainda, para pensar o conceito de figura, podemos olhar para Pêcheux (1997, p. 154) quando, ao referir-se à noção de interpelação ideológica, ele recorre a esse termo. A figura aparece em Pêcheux pela referência que ele faz à reflexão de Althusser sobre o processo de interpelação, a fim de mostrar que a figura da interpelação é como uma "ilustração", um 
2 O que tomamos como momentos de identificação aqui está relacionado ao que Pêcheux (1975) teorizou sobre as modalidades de tomada de posição do sujeito. Essas modalidades resultam, segundo o autor, da relação de desdobramento entre o "sujeito da enunciação" e o "sujeito universal", podendo ocorrer em três diferentes movimentos do sujeito. Na primeira modalidade, que caracteriza o discurso do "bom sujeito", há uma superposição, uma identificação plena entre o sujeito da enunciação e o sujeito universal, ou a forma-sujeito. Na segunda, que caracteriza o discurso do "mau sujeito", há deslocamentos, de modo que o sujeito da enunciação se contra-identifica com o sujeito universal. Na terceira modalidade, há uma desidentificação entre o sujeito da enunciação e o sujeito universal, de modo a produzir uma ruptura com os saberes/ sentidos daquele FD em que ele enunciava, passando a enunciar numa nova FD (PÊCHEUX, 1997, p. 215-217) "exemplo", ao mesmo tempo reconhecível e abstrato o suficiente para dar origem ao conhecimento.

É o caráter de ilustração tratado por Althusser e Pêcheux que entendemos presente nas figuras identitárias, produzindo, para o sujeito, a evidência do estar nesse lugar social que uma determinada figura representa. Assim, a figura aparece enquanto forma por meio da qual é possível representar, ilustrar esse lugar, que sofre, no entanto, deslocamentos ao aparecer em discursos de diferentes épocas. Ela seria, portanto, a forma material, matriz identitária de um discurso fundador que marca o imaginário que se constrói sobre um grupo social. Conforme Orlandi (2003, p. 7), "em relação à história, os discursos fundadores são discursos que funcionam como referência básica no imaginário constitutivo desse país", sendo tarefa do analista observar "como é que eles se estabilizam como referência na construção da memória nacional".

A figura personifica uma identidade local, constitui-se num lugar marcante, residual, em que essa construção identitária se apoia. As figuras não têm necessariamente uma origem única, ou são frutos de um mesmo processo de aparecimento/criação, mas compartilham o fato de terem se consolidado em determinados momentos históricos, passando a ser deles representativas, criando lugares de memória que tendem a se cristalizar. Em trabalho anterior (DE NARDI; GRIGOLETTO, 2012), recorremos a Pêcheux (2011, p. 158) para afirmarmos que, ainda que tais figuras não mais existam materialmente, a referência discursiva delas "já é construída em formações discursivas (técnicas, morais, políticas...) que combinam seus efeitos em efeitos de interdiscurso". A produção discursiva desses objetos circula, portanto, "entre diferentes regiões discursivas, das quais nenhuma pode ser considerada originária".

A figura é o resultado, assim, de uma série de processos de regularização por meio dos quais se estabelece uma memória, que, segundo Pêcheux (1999), é caracterizada por um jogo de forças entre regularização e desregulação; ou seja, a recorrência a algo pode caracterizar um movimento em que dizer o "mesmo" é dar espaço ao "jogo da metáfora". "Uma espécie de repetição vertical, em que a própria memória esburaca-se, perfura-se antes de desdobrar-se em paráfrase." (Idem, p. 53)

É pelo viés da memória, então, que sentidos, dizeres, imagens, etc. dessas figuras continuam ressoando em discursos contemporâneos, produzindo efeitos nos dizeres dos/sobre os sujeitos que se identificam ou são identificados com seu espaço de origem. Não são as figuras, portanto, que permanecem, mas suas reverberações, que podem indicar um determinado comportamento, um estilo de vida, um tipo de organização social, uma maneira de vestir, um gesto em relação à vida. Longe de serem fixas, no entanto, essas marcas deslizam, podem levar à "transfiguração" (ORLANDI, 2003, p. 7). 
A figura identitária funciona, assim, como uma espécie de resíduo resultante dos processos de cristalização de identidades locais cujos traços ressoam, pelo viés da memória, em discursos de diferentes épocas, produzindo uma matriz de sentido por meio da qual é possível representar esse lugar.

\section{O funcionamento da memória e sua relação com as figuras identitárias}

Nossa percepção do passado é a apropriação veemente daquilo que sabemos não mais nos pertencer (NORA, 1993, p. 20)

Trabalhar com a noção de figuras identitárias levou-nos a pensar sobre a memória e o modo como ela intervém no processo de produção de sentidos, promovendo a cristalização e/ou o deslocamento de determinados lugares sociais, já que os processos identitários são marcados pela historicidade, remetendo-nos ao trabalho da memória discursiva. Pelo viés da memória, pode se marcar tanto o apagamento quanto a retomada dessa historicidade, a qual tende a ser suprimida pelo desejo de unidade que atravessa o sujeito. Trabalhar com os processos de identificação é situar-se, portanto, num espaço de tensão entre cristalização e deslocamento, que é, justamente, no nosso entendimento, conforme afirmamos no item anterior, o espaço em que se situam as figuras identitárias.

Pierre Nora (1993, p. 7), ao trabalhar com a relação entre memória e história, propõe que pensemos sobre os lugares de memória e a curiosidade recente sobre eles. Essa curiosidade, para o autor, reside no fato de estarmos vivendo um momento de enfrentamento entre "a consciência da ruptura com o passado", e uma memória que, embora esfacelada, é ainda "suficiente para que se possa colocar o problema de sua encarnação". Como ele nos indica na epígrafe acima, apropriamo-nos daquilo que do passado não mais nos pertence, não mais existe enquanto concretude, mas que permanece ressoando como sinal de "reconhecimento e de

3 Para falar sobre lugares de memória, Nora (1993) faz uma distinção entre lugares e meios de memória, afirmando que a existência dos lugares só é possível pela desaparição dos meios, determinada pela aceleração de nosso tempo - mundialização, democratização, etc. - em que não há mais uma passagem regular do passado para o futuro. Já não vivemos a memória e por isso temos necessidade de consagrar-lhe lugares onde ela possa se manter. pertencimento de grupo numa sociedade que só tende a reconhecer indivíduos iguais e idênticos" (NORA, 1993, p. 13). O funcionamento dos lugares de memória ${ }^{3}$, tal como proposto por Nora, parte da consideração de que temos a necessidade de criar esses lugares porque já não mais habitamos a memória, ou seja, aquilo que insistimos em guardar nesses lugares não aparece mais em nossos rituais cotidianos, mas ainda diz sobre o passado que nos habita. Se a memória deixa de existir, criamos suportes exteriores para ela, os quais atendem, de certa forma, à nossa necessidade de lembrar. "A passagem da memória para a história obrigou cada grupo a redefinir sua identidade pela revitalização de sua própria história. O dever de memória faz cada um historiador de si mesmo." (NORA, 1993, p. 17). 
O autor, quando tematiza o conflito entre memória ehistória, coloca em causa distintos modos de reatualização do passado. Para a $\mathrm{AD}$, história e memória não se opõem, mas se complementam, se (con)fundem, já que a história é constitutiva do discurso. Como mencionamos no início deste item, interessa à $\mathrm{AD}$ trabalhar com a historicidade e não com história do ponto de vista cronológico, uma vez que importa observar não a linearidade da história, mas o modo como ela se inscreve - às vezes em pedaços, esfacelada -, nos processos discursivos. Ao falar sobre a historicidade, Orlandi (2004) reforça o fato de que o conceito aparece na AD como um modo de reafirmar a relação constitutiva entre linguagem e exterioridade. É para falar sobre a exterioridade como algo encarnado no discurso que pensamos a historicidade, então, conforme a autora, como aquilo que remete ao modo de um discurso produzir sentidos.

Com a AD - e isto que estamos chamando de historicidade - a relação passa a ser entendida como constitutiva. Desse modo, se se pode pensar em uma temporalidade, essa é uma temporalidade interna, ou melhor, uma relação com a exterioridade tal como ela se inscreve no próprio texto e não como algo lá fora, refletido nele. Não se parte da história para o texto avatar da análise de conteúdo -, se parte do texto enquanto materialidade histórica. A temporalidade (na relação sujeito/ sentido) é a temporalidade do texto. (ORLANDI, 2004, p. 55)

Então, pelo viés da historicidade, o que estamos chamando de figuras identitárias é o resultado de processos discursivos por meio dos quais se tenta reter, de um passado, aquilo que, embora não seja mais vivido, é parte de uma construção identitária. Ao serem atualizadas, as figuras marcam, no discurso, o retorno a um lugar de memória no qual o sujeito desse discurso encontra um espaço de (des)identificação: se por um lado pode, a figura, representar a marca de pertencimento a um grupo e sua história, pode, por outro, configurar-se como um espaço de recusa, um desconhecimento do passado como possibilidade de identificação com o que o sujeito entende como sendo a sua identidade. Nesse sentido, a figura designa o outro, o estranho, aquele que não se é (ou não se quer ser). Toda figura nasce, contraditoriamente, de seu desaparecimento, porque pertencia a um tempo-espaço que se transmutou. Mas nesse tempo em que vivemos, das identidades rarefeitas, da mundialização, do desaparecimento do sentido de nação, das forças globalizantes de que fala Hall (2006), parece que o efeito-contrário da dissolução das fronteiras identitárias é justamente a necessidade de recuperar a identidade de grupo, ou seja, construir lugares de memória e atualizá-los. É preciso lembrar (ou fazer lembrar).

Para a $\mathrm{AD}$, a lembrança não é nunca para o sujeito a recuperação plena daquilo que se consagrou ao esquecimento. A natureza cindida do sujeito e lacunar dos processos por meio dos 
quais se constitui, implicam a necessidade de pensar a lembrança como um retorno da memória - igualmente lacunar - ao dizer do sujeito, e não o ato solitário de rememorar. Falamos, portanto, da memória discursiva, termo que, segundo Courtine (2009, p. 105) é "distinto de toda memorização psicológica", e diz "respeito à existência histórica do enunciado no interior de práticas discursivas regradas por aparelhos ideológicos" (Idem, p.105-106). Quando tratamos da memória em $\mathrm{AD}$, estamos remetendo a esses "lugares de dizer em que os já-ditos se assentam esperando o momento de retornar pelo discurso" (DE NARDI, 2003, p. 79). São resquícios de uma história que se reatualizam no discurso por meio da relação imaginária que com ela os sujeitos estabelecem, não importando a natureza dessa história, se real ou fictícia. Formam-se, nos termos de Courtine (1999, p. 18), domínios de memória: “a exterioridade do enunciável para o sujeito enunciador da formação de enunciados 'pré-construídos', de que sua enunciação apropria-se".

Mas nem tudo se reatualiza. Todo trabalho da memória discursiva implica um efeito de esquecimento: o que se atualiza é apenas aquilo que é possível dentro do domínio da formação discursiva na qual o sujeito se inscreve. Toda lembrança traz consigo o esquecimento de algo, aquilo que não pode retornar ou, no caso das figuras, o que sobre elas o sujeito recusa como possibilidade de lembrança. Para Nora (1993, p. 12), "os lugares de memória são, antes de tudo, restos". Há, portanto, nos processos discursivos, funcionamentos que regulam que restos podem voltar à cena e quais devem permanecer nas sombras. Para Indursky (2011, p. 87), "se determinados sentidos precisam ser 'esquecidos', significa que eles desaparecem do âmbito de uma FD". Tal funcionamento, para a autora, nos permite pensar na distinção entre a memória discursiva e o interdiscurso, que, igualmente,

dizem respeito à memória social, mas não se confundem. A
memória discursiva é regionalizada, circunscrita ao que pode
ser dito em uma FD e, por essa razão, é esburacada, lacunar. Já
o interdiscurso abarca a memória discursiva referente ao complexo
de todas as FD. Ou seja, a memória que o interdiscurso compre-
ende é uma memória ampla, totalizante e, por conseguinte,
saturada." (INDURSKY, 2011, p. 87-88).

Por isso dizermos que não são as figuras propriamente que permanecem, mas suas reverberações, que se inscrevem no discurso produzindo espaços de deriva que marcam o processo de identificação do sujeito com o lugar social de que ela é marca. Ou seja, se as figuras são espaços de identificação para o sujeito e sua relação com elas se dá por um processo de transferência, ou seja, "pela existência de uma relação abrindo a possibilidade de interpretar" (PECHÊUX, 1983, p. 53), é porque há um espaço de interpretação que dá lugar ao movimento de retomada dessas figuras em diferentes espaços-tempos discursivos, colocando-nos 
4 A discussão teórica que ora empreendemos bem como as análises apresentadas foram discutidas, preliminarmente, no III Simpósio Nacional Discurso, Identidade e Sociedade, do qual resultou a publicação a qual fizemos menção em vários momentos do artigo, a saber, DE NARDI; GRIGOLETTO, 2012.

5 http://www.osultimoscangaceiros.com. br/blog/

6 Pêcheux, ao analisar a questão da memória e da repetição, comenta: "haveria, sob a repetição, a formação de um efeito de série pelo qual uma regularização se iniciaria, e seria nessa própria regularização que residiriam os implícitos, sob a forma de remissões, de retomadas e de efeitos de paráfrase (que podem a meu ver conduzir à questão da construção dos estereótipos)." (PÊCHEUX, 1999, p. 52) a questão de como se comportam, então, nos universos dos quais são parte. E é o funcionamento desses processos de transferência que nos ajuda a compreender sua permanência (ou não) como lugares de identificação (DE NARDI; GRIGOLETTO, 2012).

\section{As figuras do cangaceiro e do compadrito: algumas análises ${ }^{4}$}

A fim de podermos observar a produtividade analítica da noção de figuras identitárias, temos trabalhado com as figuras do cangaceiro e do compadrito, os quais funcionam como referência para o imaginário que se constrói sobre discursos regionais, fazendo parte da constituição identitária do sujeito nordestino, no primeiro caso, e cristalizando um sentido sobre o ser porteño, no segundo. Elegemo-los, portanto, considerando que ambos, embora diferentes, podem ser entendidos como personagens que cristalizam identidades locais, uma vez que se consolidaram em momentos históricos determinados, passando a ser deles representativas. São, assim, figuras em torno das quais se foram criando lugares de memória com tendência à cristalização. Como dissemos na primeira parte desse trabalho, não se coloca em causa a existência material dessas figuras, mas a referência discursiva a elas, que, como efeito do interdiscurso, remetem à produção de um objeto material.

Isso é o que podemos observar, por exemplo, com a figura do cangaceiro, que aparece em discursividades atuais, a exemplo daquela presente no blog "Os últimos cangaceiros" ${ }^{\prime 5}$, designação utilizada por um moto clube de Pernambuco. Na página inicial do blog, conforme podemos observar na tela abaixo, fotos antigas de Lampião e seu bando se sobrepõem às imagens dos integrantes do moto clube. A alternância entre as fotos atuais e os registros dos cangaceiros produz um interessante efeito em que presente e passado se entrecruzam, fazendo trabalhar efeitos da memória no discurso. No centro das fotografias, a marca da atualidade: a única imagem fixa é a do bando de motoqueiros pousando em frente à sua bandeira. Nela, observamos determinados elementos - como o chapéu e as armas utilizadas pelos cangaceiros - que nesse espaço representam aquilo que da figura do cangaceiro permanece como cristalização ${ }^{6}$.

A reprodução desses objetos funciona aqui como um elemento de identificação com o cangaço; trata-se de vestígios desse outro tempo-espaço que, ressignificados, fazem trabalhar a relação entre memória e atualidade. Outro elemento interessante a ser observado é a presença do mandacaru que contorna o escudo. Essa planta, símbolo do sertão nordestino, está presente, ainda, na fotografia que aparece de fundo, reconstruindo uma imagem comum nas representações do nordeste e sua gente. 


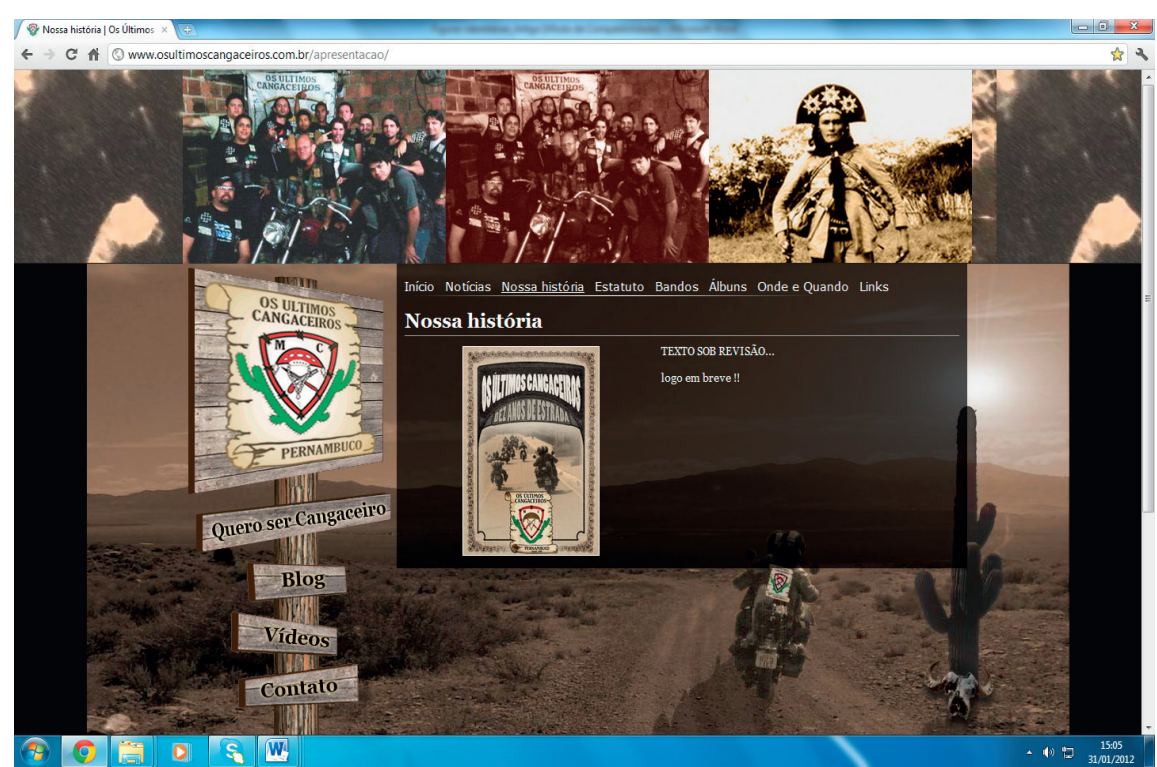

Fig. 1 - página inicial do blog "Os últimos cangaceiros"

Esses são alguns dos elementos que caracterizam o movimento de atualização do que anteriormente chamamos de marcas identitárias, pelas quais o sujeito se identifica com a figura do cangaceiro. Ainda que hoje seja apenas uma personagem histórica, essa figura inspira, pela utilização de seus emblemas, um sentimento de pertencimento a esse lugar, permitindo aos sujeitos dizerem-se através da recuperação de fragmentos de uma memória, regional e atemporal. Atemporal porque esse dizer funciona como se estivesse unindo pontas com o passado, ao mesmo tempo em que permanece reverberando sentidos no presente, rememorando elementos que desse passado ainda significam para a sua forma de se organizar enquanto grupo, enquanto bando. Símbolo da insurgência ${ }^{7}$, o cangaço parece retornar, para esse grupo, como marca de resistência, uma demonstração da fidelidade a um estilo de vida que tende a ser apagado. Sobre isso é interessante observar o que se diz, no blog, em "Quero ser um Cangaceiro":

SD1: Motociclista não é aquela pessoa que tem uma moto para apreciar a paisagem só nos finais de semana. Mas sim aquele cara que tem moto como uma extensão do seu corpo e principalmente como um estilo de vida (em seu sentido literal). Quando eu falo de estilo de vida, é o fato de você comer, beber,

7 Sobre essa questão, recomenda-se o vídeo "Conheça a história do cangaço e as duas faces de lampião", que estão entre os links que, no blog, remetem à história daqueles que lhe dão nome: http://www.osultimoscangaceiros.com br/videos/ ou http:// www.youtube.com/ watch?feature $=$ player embedded \&v $=\mathrm{HTK}$ yKj dwDGA\#!. viver, respeitar, amar, respirar a moto e seus irmãos. Por que tu achas que inúmeros Moto Clubes falam que o motociclista verdadeiro quase não se vê mais? Porque os que vivem e pertencem a esse estilo de vida, são poucos. Quer ser um de nós entre em contato e deixe sua mensagem será um prazer conversar com você! (http://www.osultimoscangaceiros.com. br/ser-cangaceiro/)

O que se verifica, na sequência acima, é realmente a atualização dessa designação "Cangaceiro", que, utilizada pelos motociclistas para autodesignarem-se, passa a representar um outro 
espaço, mantendo, no entanto, traços que unem esses homens de tempos distantes. Rebeldia e fidelidade aos seus companheiros parecem ser elementos comuns; e é pelo nome e pela recuperação de elementos materiais que caracterizavam essa vida insurgente e, ao mesmo tempo, rica e fascinante do cangaço que o elo entre os tempos se faz. Ser motociclista, no dizer desse sujeito, é também dizer não aos valores que lhe são impostos e construir uma fraternidade com aqueles que aceitam o código de conduta que lhe será imposto como condição para esse pertencimento.

Conforme Postal (2012), "a identidade está relacionada tanto com a demonstração de quem o sujeito quer ser, quanto com a bagagem de narrativas que o constituem e que podem operar na figuração efetiva de seu dizer-se". É, entendemos, nesse conjunto de dizeres que formam as narrativas sobre o cangaceiro que o sujeito do discurso em análise vai buscar o sentido de ser cangaceiro, que implica um modo de organizar-se, a conservação de um ideal comum - embora esse ideal esteja completamente ressignificado -, a fidelidade ao seu modo de vida, o respeito às regras do bando: “Dentro de nossos bandos, vale nosso CÓDIGO INTERNO". Há um retorno, portanto, a uma memória que se ressignifica, provocando deslizamentos em torno desse sentido de ser cangaceiro. Mas, como mencionamos ao citar Indursky (2011), essa memória não vem inteira, ela não rediz $\mathrm{O}$ cangaceiro, em sua existência histórico-material, mas o transforma em metáfora desse sujeito que se diz a partir de elementos que atualiza de uma memória tão prenhe de contradições. Sem a pretensão de nos aprofundarmos nessa questão, vale salientar que, em torno dessa figura do cangaceiro e da instituição do cangaço, circulam sentimentos bastante contraditórios, de repulsa e fascínio, medo e admiração, que talvez possam ser explicados a partir do papel mesmo que teve um de seus maiores expoentes, Lampião, ao mesmo tempo bandido e justiceiro.

Tais questões podem ser compreendidas pela impossibilidade de pensarmos a memória distanciada de suas condições de produção e atualização. Ao falar sobre memória discursiva, Pêcheux $(1999,52)$ afirma que ela "seria aquilo que, face a um texto que surge como acontecimento a ler, vem restabelecer os 'implícitos" (...) de que sua leitura necessita: a condição do legível em relação ao próprio legível." Ao citar Pierre Achard, o autor analisa os processos de regularização por meio dos quais se estabelece essa memória, observando, no entanto, que ela é caracterizada por um jogo de forças entre regularização e desregulação; ou seja, a recorrência de algo pode caracterizar um movimento em que dizer o "mesmo" é dar espaço ao "jogo da metáfora". "Uma espécie de repetição vertical, em que a própria memória esburaca-se, perfura-se antes de desdobrar-se em paráfrase." (Idem, p. 53) Há sempre "o outro interno em toda memória", diz Pêcheux (1999, p. 56). 
O que chamamos de figuras identitárias seriam, portanto, esses lugares de condensação de um imaginário social, ocupado por homens que dele foram (ou são) representativos e cuja imagem produz um retorno a esse lugar, ainda que nesse movimento os sentidos do estar nele se reconfigurem. É assim que, pela remissão às imagens de Lampião e seus seguidores, se atualizam no blog "Os últimos cangaceiros" algumas marcas que representam a identificação desse sujeito com um lugar social, historicamente determinado. Retorna a paisagem do sertão, os termos por meio dos quais se designam os integrantes do bando, o cuidado com a aparência - uma certa estética que se mantém nas roupas, nos chapéus, nos rifles que são agora apenas símbolos de pertencimento -, ou na interlocução proposta pelos links que podem ser abertos a partir do blog, em que encontramos tanto referência ao universo dos moto clubes, quanto a estudos e comentários sobre o cangaço. Esse sujeito, portanto, que se inscreve nas discursividades em análises, fala sobre os cangaceiros, mas se diz um deles, o que nos permite pensar que essa figura ainda produz um espaço de identificação importante entre aqueles que vivem nesse lugar.

Um movimento distinto parece caracterizar a segunda figura sobre a qual nos debruçamos: o compadrito. Nessa busca inicial que empreendemos por menções a essas figuras no espaço virtual que as estivessem atualizando, não encontramos, em relação ao compadrito, nenhum movimento que se assemelhasse ao anteriormente descrito sobre o cangaceiro, ou seja, grupos que se autodenominem "compadritos" na Buenos Aires dos dias atuais. Chama-se ao outro compadrito, ao identificá-lo por seu comportamento e/ou por sua linguagem, como se o compadrito fosse sempre um outro:

Don Dulce hablaba como un criollo aunque a Pereda no se le pasaron por alto algunas expresiones de compadrito porteño, como si don Dulce se hubiera criado en Villa Luro y llevara relativamente poco tiempo viviendo en la pampa. (BOLAÑO, 2010, p. 28)

No trecho de El gaucho insufrible, Bolaño reproduz algo que parece comum em relação a essa figura: se sabe de onde veio, quem era, como se vestia e falava, mas é raro encontrar quem se identifique com ela, embora com ela possa ser identificado. A presença dessa figura, quase sempre relacionada ao universo do tango, parece estar restrita aos que se ocupam de explicar seu surgimento e sua permanência num período de tempo já remoto, sobrevivendo apenas nas narrativas que a resgatam como símbolo de um outro tempo que não se atualiza. Se ainda há compadritos, não se escuta a sua voz, e embora se saiba quem foi essa figura e como se pode caracterizá-la, ela parece não mais funcionar como um lugar de identificação para os sujeitos contemporâneos.

Assim como outras personagens, tende o compadrito a fazer parte de um conjunto antigo de figuras que remetem a uma confi- 
8 Referimo-nos, aqui, a obras como BORGES, J. L.; BULLRICH, S. El compadrito: su destino, sus barrios, su música. Buenos Aires: Emecé Editores, 2000; CARRETERO, Andrés. M. El compadrito y el tango. Buenos Aires: Peña Lillo \& Ediciones Continente, 1999. Tais obras serviram como leituras complementares para este artigo.

9 Lacarrieu (2007) comenta que "el tango fue visualizado como un símbolo necesario para identificar a la ciudad, pero no a los ciudadanos".

10 PALACIOS, A. "O "compadrito" - O pária, as prostitutas e a cópula". Disponível em: http://blogs.estadao. com.br/ariel-palacios/o-compadrito-e-a-danca-que-era-quase-uma-2/. Acesso em: 30 de janeiro de 2012.

11 http://www.periodicodesdeboedo.com. ar/malevos-guapos-y-compadritos/. Ácesso em: 08 de fevereiro de 2012.

12 http://blogs.estadao. com.br/ariel-palacios/o-compadrito-e-a-danca-que-era-quase-uma-2/ guração desse espaço mais visível nos tempos atuais, embora sua menção e imagem não se deixem apagar. É provável que esteja na ordem do desejo ver essa multiculturalidade presente, e por isso evocá-la é um trabalho necessário para o reconhecimento desse espaço social que se quer designar. Trata-se, nos termos de Lacarrieu (2007, p. 57), da necessidade de construir-se uma matriz cultural que remeta a uma imagem que vem do passado para "reinventar el presente y desear el futuro". Esse futuro se constitui, em grande medida, conforme a autora, pelo desejo de uma Buenos Aires europeizada que por muito tempo se fez presente e à qual se pode atribuir, em certa medida, a cristalização de algumas figuras: elas não se reatualizam, mas sua presença enquanto memória de um tempo anterior se faz necessária. Conforme comenta a autora, que se ocupa das imagens e imaginários sociais que constituem a dimensão simbólica da cidade:

Esto permite congelar la población en una multiculturalidad inexistente en el presente, y también incluir la presencia de expresiones culturales ligadas a su proyección cultural, hipervisibles en los conventillos de antaño, donde cada outro puede ser estereotipado en su simplificación [...]; visualizados como el objeto del deseo, que en ausência - pues los conventillos actuales ya no albergan este tipo de mesclas - se hacen presentes. (LACARRIEU, 2007, p. 57)

Essa presença ausente é o que sentimos com o compadrito, de quem muito se $\mathrm{diz}^{8}$, sobre quem fala a literatura ou cantam os tangos, que aparece nos bailarinos que se apresentam em diversos espaços da cidade, reproduzindo traços de seu vestir e bailar, cujo linguajar deixa marcas num modo argentino de falar, mas que não aparece como um lugar social com quem ainda se identifiquem os porteños. Assim como o tango, o compadrito pertence a Buenos Aires, mas já não mais com ele se identificam os homens de Buenos Aires9.

Mas quem eram os homens assim designados. Característicos da Buenos Aires do século XIX, nem homens urbanos, nem gaúchos, os compadritos viviam nos espaços marginais, escondidos entre sombras de um lugar que parecia querer expulsá-los. Como escreve em seu blog Ariel Palacios ${ }^{10}$ : "Vivia de biscates na periferia das cidades, sem ousar entrar nas mesmas, nem pensar voltar ao campo". "Parece que estar "entre" era a condição do compadrito, entre o ser marginal ou herói, entre despertar medo ou fascínio, "Son indivíduos egocêntricos, individualistas, solitários, competitivos y fundamentalmente criollos" ${ }^{\prime 1}$.

Entendemos que esse lugar marginal que ocupa o compadrito é o que permite, como comentamos acima, que ele sirva sempre para designar o outro: aquele que não se é, o que está na margem, escondido nas sombra dos outros, esquivando-se como um bom bailarín. Nesse sentido, é interessante observar os comentários postados acerca de um texto ${ }^{12}$ em que se fala sobre o compadrito: 
- E você conhece algum 'compadrito'?

- Muitos. Às vezes eles chegam até a presidência, né?

\section{SD3}

E é verdade... às vezes os compadritos chegam à presidência. Muitas vezes não são compadritos... mas estão rodeados por vários deles, a modo de guarda pretoriana...

O que se observa é que se ainda se pode falar em compadritos e reconhecê-los, é porque há algo dessa figura que permanece, que extrapolou o espaço do texto literário e das milongas para seguir produzindo sentidos.

\section{Palavras finais}

Nesse artigo, procuramos reunir algumas reflexões que temos feito acerca do que designamos figuras identitárias, procurando mostrar como a observação dos processos discursivos, a partir da teorização sobre os lugares sociais, pode nos levar a pensar em figuras que resistem à passagem do tempo, retornando como uma memória insistente na constituição de identidades regionais mesmo em um espaço-tempo em que as identidades parecem se dissolver. Entendemos que as figuras funcionam como uma ancoragem de dizer, representação material de um lugar social que reverbera como espaço de (des)identificação para os sujeitos. Mesmo que não consigamos mais resgatar os discursos que deram existência a essas figuras, observamos que se (re)produz nos discursos atuais, pelo viés da memória, algo de muito particular que diz do pertencimento do sujeito contemporâneo ao lugar que essa figura ilustra.

Podemos dizer, portanto, que tanto diante de cangaceiros como de compadritos é possível falarmos em figuras identitárias, visto encontrarmos em relação a essas personagens processos semelhantes, entre os quais podemos destacar a sua vinculação com um período histórico específico, do qual passaram a ser a "imagem" mais presente, ou, como dissemos anteriormente, a cristalização, no tempo, de uma imagem que está colada à representação de um lugar social. É esse lugar social por elas ocupado que tais figuras ilustram, fazendo com que se (re)produza em torno de si um imaginário a ser construído sobre o grupo social de que são parte.

No entanto, as análises parciais que fizemos até agora acerca dos discursos que "atualizam" essas figuras no espaço virtual nos mostram um funcionamento distinto: enquanto a figura do cangaceiro aparece, para alguns, como um lugar de identificação ainda possível para o ser nordestino, a partir do qual é possível 
dizer-se como pertencente a um lugar, apagando ou aproveitando-se justamente da contradição que marca essa existência conflituosa do homem do cangaço - um tanto herói outro tanto bandido -, ao compadrito parece ter sido reservado o destino de designar sempre o outro, o torto, o marginal. Ainda que a literatura o tenha utilizado como personagem, ainda que sua presença viva nas vozes dos que cantam antigos tangos, parece improvável dizer-se um compadrito ${ }^{13}$. Talvez os distinga a distância temporal de sua existência e dos tempos sociais, o fato de ser o compadrito um solitário, enquanto em bandos viviam os cangaceiros, mas certamente há ainda a investigar os movimentos sócio-históricos que determinam as distintas apropriações dessas figuras nos discursos contemporâneos.

O que apresentamos aqui são apenas especulações iniciais acerca tanto da funcionalidade do conceito de figura para as análises que pretendemos empreender, como do funcionamento dessas discursividades sobre as quais começamos a nos debruçar. Mas certamente vivem nos discursos sobre esses lugares sociais e nas condições sócio-históricas de seu (des)aparecimento a possibilidade de compreender as distintas formas de atualização de uma memória que insiste em retornar. Como nos diz Nora (1993, p. 14), são "lugares salvos de uma memória na qual não mais habitamos, semi-oficiais e institucionais, semi-afetivos e sentimentais; lugares de unanimidade sem unanimismo que não exprimem mais nem convicção militante nem participação apaixonada, mas onde palpita ainda algo de uma vida simbólica."

${ }_{13}$ Com exceção de sites que remetem ao tango, encontramos apenas um blog de um Body Piercer que utiliza como autodesignação o termo compadrito. Como buscávamos a utilização dessas designações por grupos, não incluímos aqui a análise desse caso, que, no entanto, pode ser revelador do imaginário que cerca o compadrito, se considerarmos que as práticas que são divulgadas por meio do blog, a exemplo da suspensão corporal, ainda podem ser entendidas, de certo modo, como marginais.

\begin{abstract}
This article aims the discussion about the notion of identity figures, observing as the memory is involved in the production of meanings, and in the promotion of crystallization and/or displacement of certain social places. This notion is based on the concept of the figure, that we take here while crystallization, in time, of an image that is attached to representation from a social place. The figure appears as a form through which it is possible to represent this place, and the same may undergo displacements when it is discussed at different times. This is the material form of a discourse "founder" (ORLANDI, 2003) that marks the imaginary that is built on a social group. Thus, when dealing with identity figures, we plotted as central objectives of this article: 1) produce a theory about this notion in the field of $A D$, based on the relation among the concepts of figure, memory and identification; 2) explore its analytical
\end{abstract}


productivity, from the figures of the "cangaceiro" and "compadrito".

Keywords: memory; identity figures; identification.

\section{REFERÊNCIAS}

BOLAÑO, R. El gaucho insufrible. Barcelona: Editorial Anagrama, 2010.

CORACINI, M. J. A celebração do outro na constituição da identidade. In: Revista Organon. V. 17, n. 35. Porto Alegre: Instituto de Letras da UFRGS, 2003, p. 201-220.

COURTINE, J-J. O chapéu de Clémentis. In. INDURSKY, F.; LEANDRO FERREIRA, M.C. (Org.). Os múltiplos territórios da análise do discurso. Porto Alegre: Sagra Luzzatto, 1999. Coleção Ensaios, n.12, p. 15-22.

. Análise do discurso político: o discurso comunista endereçado aos cristãos. São Carlos: EdUFSCAR, 2009.

DE NARDI, F. S. Entre a lembrança e o esquecimento: os trabalhos da memória na relação com língua e discurso. In. LEANDRO FERREIRA, M. C. (Org.) Discurso, Lingua e Memória. Revista Organon, Universidade Federal do Rio Grande do Sul, vol. 17, n. 35, 2003, p. 65-85.

DE NARDI, F. S.; GRIGOLETTO, E. Figuras identitárias: a (não) manutenção de lugares sociais. Anais eletrônicos do III Simpósio Nacional e I Simpósio Internacional Discurso, Identidade e Sociedade. Campinas: USP/UNICAMP, 2012, p. 1-13.

GRIGOLETTO, E. Do lugar discursivo à posição-sujeito: os movimentos do sujeito-jornalista no discurso de divulgação científica. In: MITTMANN, S.; GRIGOLETTO, E.; CAZARIN, E.A. (Orgs.). Práticas discursivas e identitárias: sujeito e língua. Porto Alegre: Nova Prova, 2008, p. 47 -65.

HALL, Stuart. A identidade cultural na pós modernidade. $13^{\mathrm{a}}$ ed., Rio de Janeiro: DP\&A, 2006.

INDURSKY, F. A memória na cena do discurso. In. INDURSKY, F.; MITTMANN, S.; LEANDRO FERREIRA, M. C. Memória e história na/da Análise do Discurso. São Paulo: Mercado das Letras, 2011, p. 67-90.

LACARRIEU, Mónica. La "insoportable levedad" de lo urbano. EURE (Santiago), Santiago, v. 33, n. 99, agosto 2007. Disponível em <http://www.scielo.cl/scielo.php?script=sci_arttext\&pid $=$ S025071612007000200005\&lng=es\&nrm=iso $>$. Acesso em 13 fev. 2012.

NORA, P. Entre memória e história: a problemática dos lugares. Trad. Bras. De Yara Aun Khoury. In: Projeto História, No 10. Re- 
vista do Programa de Estudos Pós-Graduados em História e do Departamento de História da PUC-SP. São Paulo. Dezembro 1993, p. 7 - 28.

ORLANDI, E. O discurso fundador. Campinas: Pontes, 2003.

. Interpretação: autoria, leitura e efeitos do trabalho simbólico. $4^{\mathrm{a}}$ ed., Campinas: Pontes, 2004.

PÊCHEUX, M. (1975). Semântica e Discurso: uma crítica à afirmação do óbvio. 3. ed. Campinas: UNICAMP, 1997.

Papel da memória. In: ACHARD, P. et al. Papel da memória. Campinas: Pontes, 1999, p. 49 - 58.

Pontes, 1990.

(1983) Discurso: estrutura ou acontecimento. Campinas:

Metáfora e Interdiscurso. PÊCHEUX, M. Análise de discurso. Textos Escolhidos por Eni Orlandi. Campinas: Pontes, 2011, p.151-162.

POSTAL, R. Mascarilha e récita: estratégias contemporâneas de figuração identitária. 2012. 